José Wagner Leonel Tavares-Júnior Dhtps///orcid org/0000-0002-7405-4998

Pedro Braga-Net0,2,3

Dhttps://orcid.org/0000-0001-9186-9243

Janine de Carvalho Bonfadini ${ }^{3}$

Onttps://orcid.org/0000-0001-9789-8459

Lays Bittencourt ${ }^{4}$

- https://orcid.org/0000-0003-4448-795X

Candida Helena Lopes ${ }^{5}$

(1) https://orcid.org/0000-0002-6161-2938

Larissa Mendes 5

Dhttps://orcid org/0000-0003-0274-6837

José Ibiapina Siqueira-Neto

Ohttps://orid.org/0000-0002-6675-1136

Valéria Sousa ${ }^{4}$

Ohttps://orid.org/0000-0001-9113-7106

Anina Amaral ${ }^{4}$

Ohttps://orcid.org/0000-0001-5932-7751

Carolina Gomes Carrilho ${ }^{6}$

(1) https://orcid.org/0000-0001-9833-7645

Jonatan Oliveira Espindola ${ }^{6}$

(D) https://orcid. org/0000-0001-6155-7433

Maria Eduarda Avancini Casali ${ }^{6}$

Onttps://orid.org/0000-0002-5614-5474

André Barciela Veras ${ }^{6}$

OChttps://orcid.org/0000-0002-4986-7639

Gilberto Sousa Alves, 1,4,7

Dhttps://orcid.org/0000-0002-0463-6183

\section{Clinical characteristics and diagnostic accuracy of the revised Addenbrooke Cognitive Examination (ACE-R) in older adults with a low educational level}

\author{
Características clínicas e acurácia do Exame Cognitivo Addenbrooke \\ Versão revisada (ACE-R) em idosos com baixa escolaridade
}

DOI: $10.1590 / 0047-2085000000310$

\begin{abstract}
Objective: To determine the diagnostic accuracy of the Addenbrooke's Cognitive Examination Revised (ACE-R) as a cognitive screening tool for older adults with low levels of schooling and healthy aging, $\mathrm{MCl}$ and dementia in Brazil. Methods: All participants underwent neurological and psychiatric examinations and were administered a validated version of ACE-R. Results: A total of 85 participants were evaluated; most were females $(84.7 \%, n=72)$. The post hoc analysis showed statistical differences in ACE-R total scores between older adults with mild cognitive impairment (MCI) and controls $(p<0.001)$ and in subitem scores including verbal fluency, language, visuospatial skills and attention ( $p<0.001)$. The visual-spatial skills subitem was the most strongly correlated with schooling level $(r=0.509, p<0.001)$, whereas late, immediate recall and recognition memory were not influenced by schooling. The ACE- $R$ had the best diagnostic accuracy in discriminating between $\mathrm{MCl}$ and controls $=0.69(<57.5 ; 80 / 66), \mathrm{MD}$ and controls $=0.98(<50 ; 100 / 96), \mathrm{MCl}$ and $\mathrm{MD}=0.86(<49.5 ; 100 / 74)$. Conclusions: ACE-R and Mini-Mental State Examination (MMSE) scores for older adults with $\mathrm{MCl}$ and controls were significantly lower than those reported in similar studies. These preliminary findings support the need for establishing reliable cut-off scores for cognitive assessment of older Brazilian adults with low schooling at risk for dementia taking into consideration ecological and local variables.
\end{abstract}

\section{KEYWORDS}

Dementia, cognitive screening, illiterate, Northeast, Addenbrooke, accuracy.

\section{RESUMO}

Objetivo: Determinar a precisão diagnóstica do Exame Cognitivo de Addenbrooke (ACE-R) como uma ferramenta de triagem cognitiva para adultos idosos com baixos níveis de educação e envelhecimento saudável, $\mathrm{MCl}$ e demência no Brasil. Métodos: Os indivíduos submeteram-se à avaliação clínica e psiquiátrica e foi administrada uma versão validada da versão revisada da bateria cognitiva ACE- $R$ (ACE-R). Resultados: Oitenta e cinco indivíduos foram avaliados, predominando as mulheres $(84,7 \%, \mathrm{n}$ =72). Na análise post hoc, controles e CCL exibiram diferenças estatísticas nos escores globais do ACE-R ( $p<0,001$ ) e seus subdomínios, incluindo fluência verbal, linguagem, habilidades visuoespaciais e atenção $(p<0,001)$. A habilidade visuoespacial foi o item mais correlacionado com a escolaridade $(r=0,509$, $p<0,001)$, enquanto a memória tardia, de recordação e reconhecimento não foi influenciada pela educação. A precisão do ACE-R produziu melhores resultados para CCL versus controles $=0,69(<57,5$; 80/66), demência versus controles $=0,98(<50 ; 100 / 96)$, $C C L$ versus demência $=0,86(<49,5 ; 100 / 74)$. Conclusões: Os escores de ACE-R e MMSE para controles e CCL foram consideravelmente inferiores aos encontrados em estudos semelhantes. Resultados preliminares confirmam a necessidade de estudos brasileiros estabelecerem pontos de corte confiáveis para baterias cognitivas em idosos com baixa escolaridade e em risco de demência, reconhecendo variáveis ecológicas e regionais.

PALAVRAS-CHAVE

Demência, triagem cognitiva, analfabetos, Addenbrooke, acurácia.

\section{Received in: April/14/2020. Approved in: July/26/2020}

1 Federal University of Ceara, Department of Clinical Medicine, Section of Neurology, Fortaleza, CE, Brazil.

2 Ceara State University, Center of Health Sciences, Fortaleza, CE, Brazil.

3 Walter Cantídio University Hospital (HUWC), Fortaleza, CE, Brazil.

4 Federal University of Maranhão, Translational Psychiatry Research Group, São Luís, MA, Brazil.

5 University Center of Maranhão (CEUMA), São Luís, MA, Brazil.

6 Dom Bosco Catholic University (UCDB), Campo Grande, MS, Brazil.

7 Federal University of Rio de Janeiro, Institute of Psychiatry, Graduate Program in Psychiatry and Mental Health (PROPSAM), Rio de Janeiro, RJ, Brazil.

Address for correspondence: Gilberto Sousa Alves. Praça Gonçalves Dias, 21 - Centro - 65020-240 - São Luís, MA, Brazil. E-mail: gsalves123@hotmail.com; Phone: ++5598 32728000; Fax: ++55 9832726001 


\section{INTRODUCTION}

The increase in life expectancy in Brazil has been associated with a higher prevalence of age-related mental conditions such as Alzheimer's disease (AD) ${ }^{1,2}$. Brazil is one of 10 countries with the largest population of older adults in the world (WHO-UN). According to the Brazilian Institute of Geography and Statistics (IBGE) data from the 2000 Population Census, $9.7 \%$ of Brazil's population is 60 years old or more 3 . By 2020, the Brazilian population of older adults aged 60 or more is projected to reach 29.8 million, and those over 80 are expected to reach 4.7 million $^{4}$, and around 3 million people (11\%) will have dementia. In the Northeast city of Fortaleza, it is estimated that at least 23,000 adults have dementia ${ }^{3}$.

$A D$ is the most common type of dementia syndrome accounting for about 50\% to $70 \%$ of dementia cases, alone or in combination ${ }^{5}$. Mild cognitive impairment (MCl) is considered an intermediate stage between healthy aging and dementia-9. The prevalence of $\mathrm{MCl}$ in people over 65 years of age is $12-18 \%{ }^{10}$, and the annual rate of progression from $\mathrm{MCl}$ to $\mathrm{AD}$ is $10-15 \% \%^{7,11}$. In Brazil, the estimated incidence rate of $\mathrm{MCl}$ is $13.2 \%^{12}$. Early detection of $\mathrm{MCl}$ in older adults using validated screening tests is of great importance since this population group could benefit from new drugs that are being investigated for the treatment of degenerative diseases such as AD. Also, evidence shows that, since $\mathrm{MCl}$ is a transitional stage between normal aging and $A D$, there is less brain involvement and those affected are theoretically more likely to benefit from drug therapies?

Cognitive tests are commonly used for screening cognitive impairment, etiological diagnosis, establishing disease severity and monitoring disease progression ${ }^{13}$. A major challenge for the initial assessment of age-related cognitive disorders is to select a screening test that is both sensitive and specific for differential diagnosis. Ceiling and floor effects limit the ability of a test or some of its items to accurately assess cognitive impairment ${ }^{14}$. The ceiling effect occurs when score distribution is skewed and variance in a cognitive domain is no longer "achieved", thereby preventing to assessment test performance. This effect has been reported in several studies and is primarily related to educational background. Another important aspect is the need for cognitive assessment tests that are fast tools that do not require specialized training and have the ability to accurately discriminate adults with healthy aging, $\mathrm{MCl}$ and dementia.

In Brazil, several epidemiological studies have investigated age-related memory changes in older adults. In a study by Almeida ${ }^{15}$, Mini-Mental State Examination (MMSE) cutoff scores of 23-24 yielded $84 \%$ sensitivity, but low specificity (60\%) to discriminate between $\mathrm{MCl}$-normal aging and dementia. Brucki ${ }^{14}$ reported that schooling level was the most important factor influencing MMSE scores (ANOVA F[4,
425] 100.45, p < 0.0001), and cutoff scores for illiterate people (score $=20$ ) were the lowest across all groups evaluated.

Few cognitive screening studies of dementia and neuropsychiatric disorders in older adults have been conducted outside major metropolitan areas in Brazil, including most northeastern cities. ${ }^{16}$ This is mainly because these studies involve expensive assessments in specialized services. We conducted an electronic search in the PUBMED database and found only two studies conducted in Northeast Brazil - one from 2005 by Brito-Marques and Cabral Filho ${ }^{17}$ and another one from 2012 by Caldas et al. ${ }^{18}$. Cognitive assessment of adults who are either illiterate or with low levels of schooling poses additional challenges. About 14 million people are estimated to be illiterate in Brazil and a large proportion of them are older adults. Together with aging, educational background is a known important variable associated with cognitive decline. Despite the large proportion of older adults who are either illiterate or with low levels of schooling in Brazil (20.4\%), there is great controversy about reliable approaches for cognitive assessment of this population. Previous studies have sought to establish valid cutoff scores for illiterate adults ${ }^{1,2}$, but there is no consensus on whether data can be replicable in populations from different regions nationwide. Sociocultural aspects, e.g., living in rural areas and having limited access to the internet, banking services and public transportation, may influence cognitive performance ${ }^{19}$.

The existing body of evidence supports the study of psychometric properties of cognitive instruments available to make their use practical and adapted to the local reality ${ }^{18}$, especially in Northeast Brazil, as well as to avoid educational bias usually seen in cognitive scales validated to the Brazilian population. Our study aimed to determine the diagnostic accuracy of the Addenbrooke's Cognitive Examination Revised (ACE-R) as a cognitive screening tool for older adults with low levels of schooling and healthy aging, $\mathrm{MCl}$ and dementia in Brazil. This study will be also supported by data from our research project - the Addencog project. Our main hypothesis is that specific cutoff scores can be used for cognitive assessment of older adults with low levels of literacy living in Northeast Brazil.

\section{METHODS}

The Addencog research project is a multicenter initiative conducted in two metropolitan areas in Northeast Brazil the city of São Luís (state of Maranhão) and Fortaleza (state of Ceará). Participants were older adults consecutively recruited in 3 community centers from January 2018 to April 2019 as well as patients attending two geriatric neuropsychiatry outpatient services. The present study evaluated a total of 87 participants comprising 9 adults with mild dementia (MD) (4 from Fortaleza and 5 from São Luís), 49 with MCl (24 from 
Fortaleza and 25 from São Luís) and 29 healthy aging controls (14 from Fortaleza and 15 from São Luís). Sociodemographic information was collected from medical history and clinical examination through an interview conducted by a geriatric psychiatrist and three senior neurologists (GSA, JISN, PB and WL). The ACE-R was used to assess different cognitive domains including memory, attention, language, verbal fluency and visuospatial skills ${ }^{20}$. All participants underwent neurological and psychiatric examination and imaging studies (computerized tomography or magnetic resonance imaging). They were initially evaluated using the Clinical Dementia Rating (CDR) and the Functional Activities Questionnaire $(\mathrm{FAQ})^{21}$ to assess functional ability and were categorized as cognitively healthy, $\mathrm{MCl}$ and $\mathrm{MD}$ if $C D R=0, C D R=0.5$ and $C D R=1$, respectively. Healthy and $\mathrm{MCl}$ participants showed normal FAQ scores whereas those with MD had scores $>5$ in FAQ, which suggests impaired functional ability. The ACE-R and MMSE were then administered to all participants; these instruments were not used to establish a diagnosis. Only those with up to 5 years of formal schooling (verified by family members) were considered eligible for the study. $\mathrm{MCl}$ diagnosis was based on Petersen criteria ${ }^{6}$. We used weighted scores to interpret MMSE results for illiterate participants as described by Brucki et al. ${ }^{14}$ and confirm healthy aging status or $\mathrm{MCl}$. The diagnosis of dementia was based on the Diagnostic and Statistical Manual of Mental Disorders (DSM-IV) and the International Statistical Classification of Diseases and Related Health Problems (ICD-10) criteria ${ }^{22,23}$. The main exclusion criteria were neurological diseases such as a history of stroke, traumatic brain injury, epilepsy, multiple sclerosis, or previous psychiatric conditions (major depression, bipolar disorder, schizophrenia, or alcohol dependence). As the total ACE-R score and its subitems and MMSE scores exhibited normal curve distribution in the Kolmogorov Smirnov Test, parametric testing was performed, with Pearson correlation and ANOVA independent group test with Bonferroni correction for multiple comparisons being performed. A p-value $<0.05$ was adopted as statistically significant. SPSS version 26.0 was carried out for calculation.

The study was approved by the National Research Ethics Committee (CAAE: 75982215.2.0000.5054) and followed the Declaration of Helsinki. All participants received information of the study protocol before signing the consent form.

\section{RESULTS}

\section{Sociodemographic characteristics}

Table 1 shows the main clinical characteristics of the study participants. A total of 87 participants were evaluated (mean age $73.16 ;$ SD 8.71). The mean age was lower among controls compared to $\mathrm{MCl}$ and $\mathrm{MD}$ participants, but this difference was not statistically significant. There were no other significant differences in age and education.

The majority of the participants were married, homemakers, diagnosed with $\mathrm{MCl}$, and had at least 2 medical comorbidities (most commonly hypertension, dyslipidemia, or thyroid disorders) (Table 1). Their mean income was 493.26 US dollars (SD 502.78), which is considered an average income level in Brazil ${ }^{24}$.

\section{Correlation between variables}

Schooling was moderately correlated with MMSE $(0.481, \mathrm{p}$ $\leq 0.001)$ and ACE-R scores $(0.484, p \leq 0.001)$. In the ACE-R, the subitem most strongly correlated with the literacy level was visuospatial skills $(r=0.509, p<0.001)$. Conversely, other subitems such as immediate memory, late anterograde memory, and recognition memory were less influenced by schooling level $(p>0.05)$.

\section{Controls versus $\mathrm{MCl}$}

Controls showed mean MMSE scores of 25.66 (Table 2), which were significantly higher than those for $\mathrm{MCl}$ and MD participants (Table 2). Mean ACE-R scores and subitem scores for attention, memory, verbal fluency, language and visuospatial skills were higher in controls than $\mathrm{MCl}$ participants (Table 2).

\section{Receiver operating characteristic (ROC) curve analysis}

We assessed sensitivity and specificity for the MMSE and ACE-R using receiver operating characteristic (ROC) curves (Figures 1 and 2). Optimal sensitivity and specificity values were defined based on Youden's index ${ }^{25}$ : J: $\max \left\{\text { sensitivity }_{i}+\text { specificity }-1\right\}_{1}$ where $i$ represents the pair of coordinates on the graph.

When we compared $\mathrm{MD}$ versus $\mathrm{MCl}$, the area under the ROC curve (AUC) for the MMSE was 0.84, which is considered very good using Meyers' scale ${ }^{26}$; it showed 0.89 sensitivity and 0.85 specificity for a cutoff score of 19.5 (Figure 3). For the $A C E-R$, the AUC was 0.86 , which is considered very good ${ }^{26}$; it showed 1.00 sensitivity and 0.74 specificity for a cutoff score of 49.5 (Figure 3).

When we compared MD versus controls, the AUC for the MMSE was 0.96, which is considered excellent using Meyers' scale ${ }^{26}$; the MMSE showed 0.89 sensitivity and 1.00 specificity for a cutoff score of 20 (Figure 1). For the ACE-R, the AUC was 0.98 , which is considered excellent ${ }^{26}$; it showed 1.00 sensitivity and 0.96 specificity for a cutoff score of 50 (Figure 1).

When we compared $\mathrm{MCl}$ versus controls, the AUC for the MMSE was 0.69, which is considered not good ${ }^{26}$; it showed 0.96 sensitivity and 0.34 specificity for a cutoff score of 26.5 (Figure 2). For the ACE-R, the AUC was 0.69, which is considered not good ${ }^{26}$; it showed 0.80 sensitivity and 0.66 specificity for a cutoff score of 57.5 (Figure 2). 
Table 1. Socio demographic characteristics

\begin{tabular}{|c|c|c|c|c|}
\hline \multirow[b]{2}{*}{ Variable } & \multicolumn{4}{|c|}{ Group Frequency (\%) } \\
\hline & $\begin{array}{c}\text { Controls } \\
29(33.33)\end{array}$ & $\begin{array}{c}\text { MCI } \\
49 \text { (56.32) }\end{array}$ & $\begin{array}{c}\text { Dementia } \\
9 \text { (10.34) }\end{array}$ & $\begin{array}{c}\text { Total } \\
87 \text { (100) }\end{array}$ \\
\hline & $25(28.73)$ & $41(47.13)$ & $8(9.19)$ & $74(85.05)$ \\
\hline \multicolumn{5}{|l|}{ Gender (women) } \\
\hline \multicolumn{5}{|l|}{ Ethnicity } \\
\hline Black African & $8(9.19)$ & $6(6.90)$ & $1(1.15)$ & $15(17.24)$ \\
\hline Brown & $14(16.09)$ & $35(40.23)$ & $4(4.60)$ & 53 (60.92) \\
\hline White and other & $7(8.05)$ & $8(9.19)$ & $4(4.60)$ & $19(21.84)$ \\
\hline \multicolumn{5}{|l|}{ Marital status } \\
\hline Married & $13(14.94)$ & $11(12.64)$ & $7(8.05)$ & $31(35.63)$ \\
\hline Widowed & $9(10.34)$ & $5(5.75)$ & $2(2.30)$ & $16(18.39)$ \\
\hline Divorced & $3(3.45)$ & $13(14.94)$ & 0 & 16 (18.39) \\
\hline Single & $4(4.60)$ & $20(22.99)$ & 0 & $24(27.59)$ \\
\hline \multicolumn{5}{|l|}{ Previous occupation } \\
\hline Employed & $7(8.05)$ & $6(6.90)$ & $2(2.30)$ & $15(17.25)$ \\
\hline Domestic worker & $13(14.94)$ & $26(29.88)$ & $6(6.90)$ & $45(51.72)$ \\
\hline Self employed & $5(5.75)$ & $10(11.49)$ & $1(1.15)$ & $16(18.39)$ \\
\hline Employer & $4(4.60)$ & $7(8.05)$ & 0 & $11(12.65)$ \\
\hline \multicolumn{5}{|l|}{ Comorbidities } \\
\hline Less than one & $5(5.75)$ & $4(4.60)$ & 0 & $9(10.35)$ \\
\hline 1 comorbidity & $9(10.34)$ & $16(18.39)$ & $5(5.75)$ & $30(34.48)$ \\
\hline$\geq 2$ comorbidities & $15(17.24)$ & $29(33.33)$ & $4(4.60)$ & $48(55.17)$ \\
\hline Hypertension & $20(22.99)$ & $30(34.48)$ & $5(5.75)$ & $55(63.22)$ \\
\hline Dyslipidemia & $8(9.19)$ & $18(20.69)$ & $2(2.30)$ & $28(32.18)$ \\
\hline Diabetes & $4(4.60)$ & $5(5.75)$ & $1(1.15)$ & $10(11.50)$ \\
\hline Thyroid and osteo metabolic diseases & $1(1.15)$ & $14(16.09)$ & 0 & $15(17.24)$ \\
\hline Other medical comorbidities & 0 & $10(11.49)$ & 0 & $10(11.49)$ \\
\hline Family report of dementia & $7(8.05)$ & $12(13.79)$ & $1(1.15)$ & 20 (22.99) \\
\hline Alcohol use (previous or current use) & $7(8.05)$ & $16(18.39)$ & $1(1.15)$ & $24(27.59)$ \\
\hline Tobacco (previous or current use) & $8(9.19)$ & $12(13.79)$ & $5(5.75)$ & $25(28.73)$ \\
\hline
\end{tabular}

Table 2. Socio demographic and cognitive profile and group comparisons

\begin{tabular}{|c|c|c|c|c|c|c|c|}
\hline \multirow{2}{*}{ Variable } & \multirow{2}{*}{$\begin{array}{c}\begin{array}{c}\text { Controls } \\
(\mathrm{n}=29)\end{array} \\
\text { Mean (SD) }\end{array}$} & \multirow{2}{*}{$\begin{array}{c}\begin{array}{c}\text { MCI } \\
(\mathrm{n}=49)\end{array} \\
\text { Mean (SD) }\end{array}$} & \multirow{2}{*}{$\begin{array}{c}\begin{array}{c}\text { Dementia } \\
(\mathrm{n}=9)\end{array} \\
\text { Mean (SD) } \\
\end{array}$} & \multirow[t]{2}{*}{$\mathbf{F}$} & \multicolumn{3}{|c|}{ Significance - p level* } \\
\hline & & & & & Con vs. MCI & MCI vs. Dem & Dem vs. Con \\
\hline Age & $70.48(6.69)$ & $74.76(9.30)$ & $73.11(9.95)$ & 2.253 & 0.110 & 1.000 & 1.000 \\
\hline Education (years) & $2.90(2.16)$ & 2.55 (1.72) & 2.33 (2.23) & 0.422 & 1.000 & 1.000 & 1.000 \\
\hline MMSE & $25.66(2.47)$ & $22.02(3.48)$ & $17.22(3.42)$ & 27.127 & $<0.001$ & $<0.001$ & $<0.001$ \\
\hline ACE-R & $70.14(13.02)$ & $52.49(11.00)$ & $39.89(6.86)$ & 33.181 & $<0.001$ & 0.009 & $<0.001$ \\
\hline Attention-orientation & $14.86(1.86)$ & $12.57(2.11)$ & $9.22(1.71)$ & 29.837 & $<0.001$ & $<0.001$ & $<0.001$ \\
\hline Memory component I & $11.45(3.59)$ & $8.39(3.01)$ & $6.44(1.67)$ & 12.679 & $<0.001$ & 0.269 & $<0.001$ \\
\hline Memory component II & $6.85(2.51)$ & $4.40(2.17)$ & $4.56(1.88)$ & 9.698 & $<0.001$ & 1.000 & 0.033 \\
\hline Memory (total) & $17.58(6.10)$ & $11.97(4.51)$ & $11.00(2.64)$ & 13.118 & $<0.001$ & 1.000 & 0.002 \\
\hline Verbal Fluency & $7.89(2.79)$ & $4.98(3.05)$ & 2.78 (1.92) & 14.435 & $<0.001$ & 0.112 & $<0.001$ \\
\hline Language & $19.14(4.86)$ & $14.98(4.21)$ & 9.78 (2.33) & 18.421 & $<0.001$ & 0.004 & $<0.001$ \\
\hline Visuo-spatial skills & $10.90(2.66)$ & $8.65(2.59)$ & $7.11(1.62)$ & 10.622 & 0.001 & 0.294 & 0.001 \\
\hline
\end{tabular}

${ }^{*} p$ values according to group comparisons after post hoc Bonferroni correction; ACER: Addenbrooke cognitive battery - revised; MMSE: Mini Mental State Exam; MCl: Mild Cognitive Impairment; Attentionorientation: composite score; Memory component I: immediate recall. retrograde and anterograde; Memory component II: late recall e recognition; Memory total: composite score. 


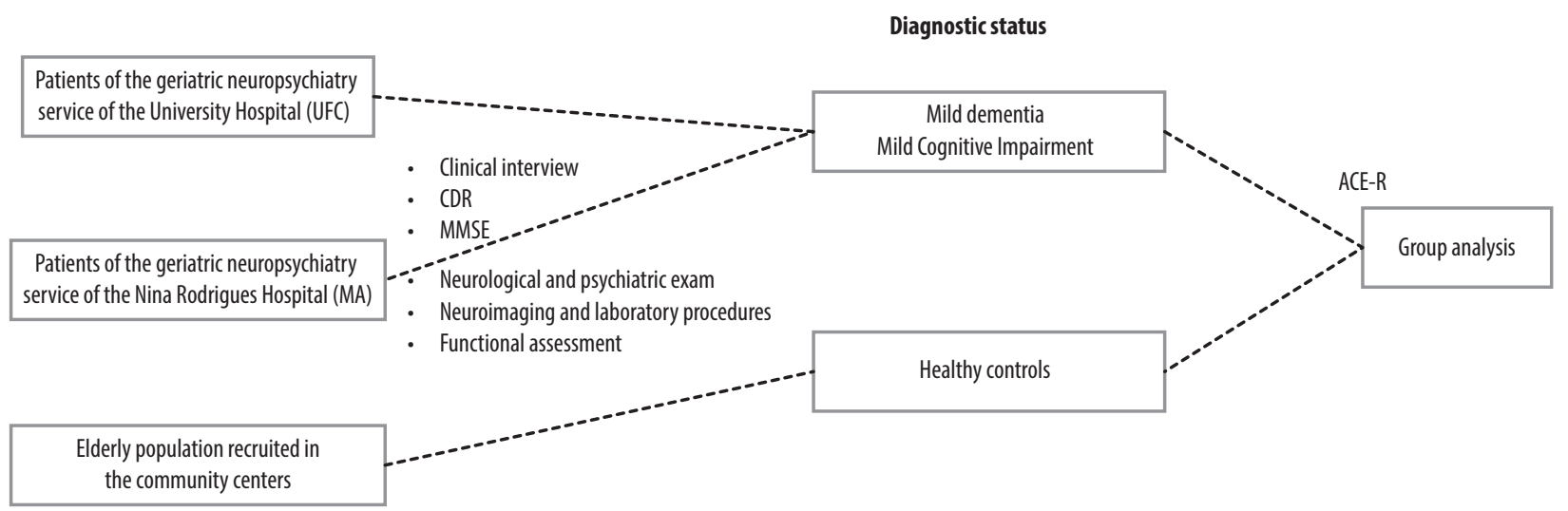

CDR: Clinical Dementia Rating scale; UFC: Universidade Federal do Ceará; MMSE: Mini-Mental State Exam; ACE-R: Addenbrooke's Cognitive Examination Revised.

Figure 1. Flowchart depicting the study design
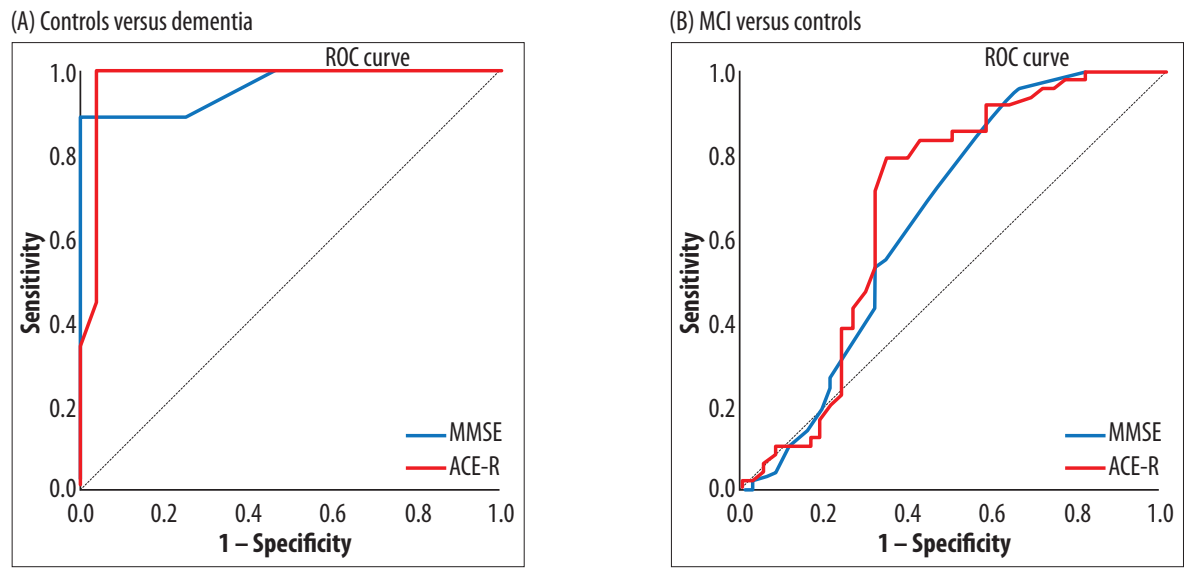

(C) MCl versus dementia

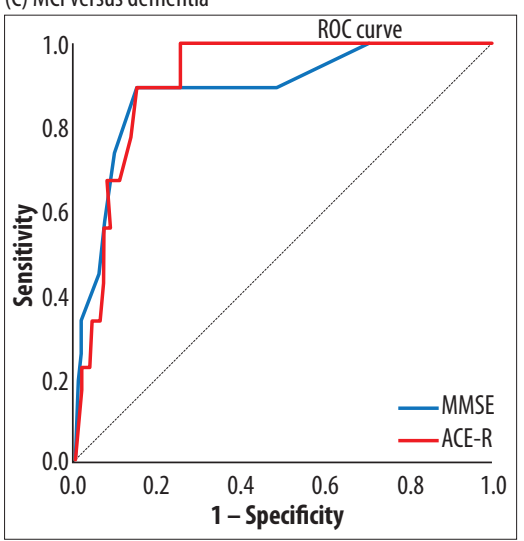

Figure 2. ROC curve of MMSE and ACE-R (for statistical details, see results).

\section{ASSESSMENT OF EDUCATIONAL LEVEL}

In a linear regression model, ACE-R and MMSE total scores were considered dependent variables and CDR, years of schooling, income, and gender were considered independent variables. We found that $60 \%$ of the sample variance could be attributed to two main individual variables, CDR and years of schooling (Table 3 ). 
Table 3. Logistic regression models of the factors related to the ACER and MMSE global scores

\begin{tabular}{|c|c|c|c|c|c|c|}
\hline \multirow{2}{*}{ Hierarchical models } & \multicolumn{3}{|c|}{ ACE-R } & \multicolumn{3}{|c|}{ MMSE } \\
\hline & B $(\beta)$ & R2 (adj R2) & F change & B $(\beta)$ & R2 (adj R2) & F change \\
\hline 1. Cognitive status (CDR) & $-33.08(-0.72)$ & $0.52(0.51)^{\Delta}$ & 70.67 & $-8.24(-0.67)$ & $0.45(0.44)^{\Delta}$ & 51.78 \\
\hline 2. $\mathrm{CDR}$ & $-31.65(-0.69)$ & $0.60(0.59)^{\S}$ & 12.19 & $-7.71(-0.62)$ & $0.59(0.58)^{\Delta}$ & 22.84 \\
\hline Education* & $2.15(0.27)$ & & & $0.80(0.39)$ & & \\
\hline
\end{tabular}

CDR: Clinical dementia Rating; ACER: Addenbrooke cognitive battery - revised; MMSE - Mini Mental State Exam. Significant differences expressed in $\alpha$ levels: $\S_{p} \leq 0.01 ; \Delta p \leq 0.001$. ${ }^{\star}$ Education in years.

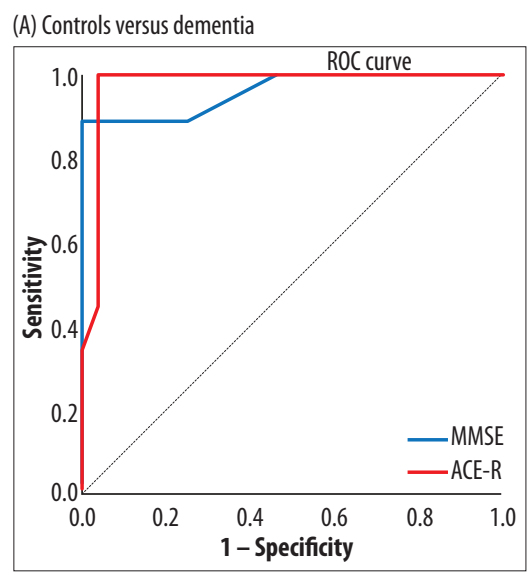

AUC for ACE-R: 0.98; highest sensibility: 1.00 and specificity points: 0.96 ; cutoff point ACE-R: 50.

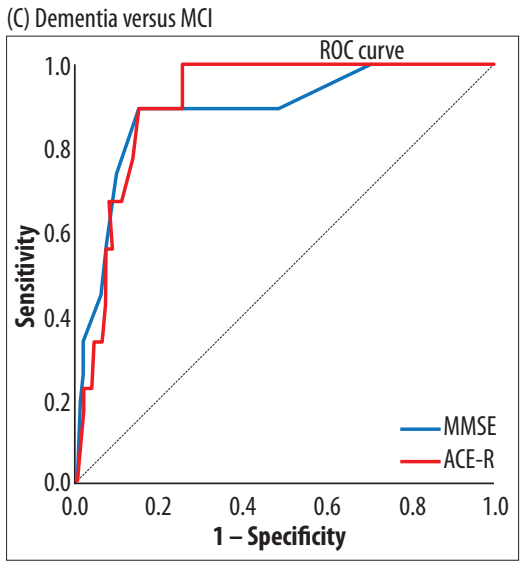

AUC: 0.86 (ACE-R); highest sensibility: 1.00 and specificity: 0.74 ; cutoff point: 49.5 .

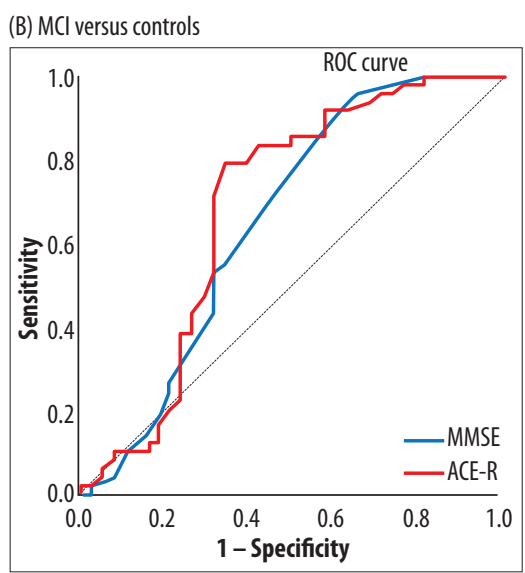

AUC for ACE-R: 0.69 ; highest sensibility: 0.80 and specificity: 0.66; cutoff point: 57.5 .

Figure 3. (A), (B) and (C) - accuracy of ACE-R between clinical groups and the area under the curve (AUC) are depicted (for detailed description, please refer to the results section).

\section{DISCUSSION}

Our study assessed the cognitive performance of a sample comprising cognitively healthy, $\mathrm{MCl}$ and $\mathrm{MD}$ participants using a short cognitive tool (ACE-R). The subitem with the strongest correlation with the educational level was visuospatial skills. The diagnostic accuracy of the MMSE and ACE-R was substantially lower than that reported in previous Brazilian studies with ACE-R. Overall, our preliminary findings underline the importance of establishing different cutoff scores for the interpretation of test results using standard cognitive instruments taking into consideration factors related to the local context. Such adaptations can provide more robustness for the diagnosis of $\mathrm{MCl}$ and dementia and facilitate early therapeutic interventions.

Overall, mean scores among adults with $\mathrm{MCl}$ from both cities in our study (São Luís and Fortaleza) are considerably lower than those described in the literature. International 
studies, such as Alexopoulos et al. study, have reported higher mean ACE-R scores for cognitive performance ${ }^{27}$ (controls $90.37 \pm 4.99 ; \mathrm{MCl} 81.34 \pm 9.09$; dementia $64.80 \pm$ 11.32). In Brazil, three studies by Caramelli et al. investigated ACE-R performance among Brazilian patients ${ }^{20,28,29}$. In their first study, an adapted ACE-R version was used and they found a mean total score of $83.3 \pm 10.0$ for a total of 114 patients (age $75.4 \pm 7.1$; years of schooling $8.5 \pm 4.3$ ) $^{29}$. In a second study with 144 healthy older adults ${ }^{28}$, they found higher ACE-R scores among adults 60 to $69(80.25 \pm 9.27)$ and 70 to 79 (78.75 \pm 7.55$)$ when compared to our study (70.14 \pm 13.02$)$. Furthermore, Carvalho conducted a study with more educated participants (mean years of schooling 8.5 vs. 2.5$)^{29}$, and found higher MMSE scores (26.9 vs. 22.0); a comparison of their results with our sample subset of health controls showed slightly lower scores for memory (20.0 vs. 17.58), verbal fluency (10.1 vs. 7.9), language (22.9 vs. 19.1) and attention/orientation (16.5 vs. 14.86). In our sample, the participants with $A D$ also showed a performance below the described in the study with lower total scores in the MMSE (21.8 vs. 17.2) $)^{29}$, and lower scores for verbal fluency (6.4 vs. 2.7), language (19.9 vs. 9.7) and visuospatial skills (12.8 vs. 7.1$)^{30}$. A recent study assessing the diagnostic accuracy of the ACE-R in patients with $\mathrm{MCl}$ who later transitioned to $A D$ (MCl-AD) and 90 adults with mild probable $A D^{20}$ reported the following scores: MCl-AD vs. controls $=0.755(<87 ; 100.0 / 45.9) ; A D$ vs. controls $=0.864(<80 ; 77.7 / 79.6) ; \mathrm{MCl}-\mathrm{AD}$ vs. $\mathrm{AD}=0.738(<76$; $60.0 / 84.2)^{20}$. Another study conducted in Southeastern Brazil evaluated older adults with different levels of schooling and included patients with cognitive impairment, no dementia (CIND), AD and healthy controls. The scores for those with less than 5 years of schooling ${ }^{31}$ were: CIND vs. controls $=$ $0.720(<65 ; 76 / 60)$; and dementia vs. controls $=0.869(<55$; 85/76). Concerning ACE-R subitems, we cannot compare our data findings with data from this study because they used a different categorization of levels of schooling in the analysis. Declining scores for illiterate adults or adults with low levels of education are associated with greater risk of conversion to dementia ${ }^{32,33}$. Faster cognitive decline has been associated with higher risk of $A D$ (rate of risk 4.526, 95\% confidence interval $[95 \% \mathrm{Cl}] 2.993,6.843, \mathrm{p}<0.001$ ) and $\mathrm{MCl}$ (rate of risk $2.971,95 \% \mathrm{Cl} 1.509,5.849, \mathrm{p}=0.002)^{32}$. Each added year of education represents a delay in the rate of accelerated decline of around 0.21 years 34 ; an individual with 4 years of education may have a rate of accelerated decline before conversion to dementia of around 6.4 years ${ }^{34}$.

To the best of our knowledge, this is the first multicenter study to assess the performance characteristics of a global cognitive screening tool in adults from Northeast Brazil. However, our study has some limitations that deserve consideration. First, we cannot establish causeeffect relationships from cross-sectional data. Second, the statistical power of our sample did not allow us to assess performance in subgroups of adults with cognitive impairment (amnestic or non-amnestic $\mathrm{MCl}$ ). Third, our sample included a few adults with dementia, which does not allow for generalization of our data findings for these individuals. Fourth, the participants' level of schooling was self-reported. Most studies do not consider the quality of literacy while studying adults with low levels of schooling, which may lead to an underestimation of the effect of this variable. Also, more recent research has investigated other variables including language skill ${ }^{33}$, vocabulary ${ }^{35}$, cognitive reserve ${ }^{34}$, abstraction ability and formal-logical operational capacity deemed to be more sensitive to establish educational status.

\section{CONCLUSIONS}

In conclusion, our study assessed ACE-R performance in dementia, $\mathrm{MCl}$ and cognitively healthy adults. Average scores for healthy aging were considerably lower than those reported in prior Brazilian studies conducted with similar methodology. The analysis of ACE-R diagnostic accuracy between groups also evidenced lower cutoff scores compared to benchmark Brazilian studies. Our preliminary findings underline the need for more studies about cognitive changes in older adults with low levels of schooling and risk for dementia. The ecological value of these studies as well as potential variables associated with performance, such as cultural characteristics and heterogeneity of illiterate groups, should be considered. These studies can provide additional evidence to support screening approaches and facilitate early diagnosis and therapeutic intervention.

\section{INDIVIDUAL CONTRIBUTIONS}

José Wagner Leonel Tavares-Júnior - Sample selection, manuscript writing.

Pedro Braga-Neto - Study design, manuscript writing and revision.

Janine de Carvalho Bonfadini - Cognitive assessment.

Lays Bittencourt - Cognitive assessment.

Candida Helena Lopes - Study supervision.

Larissa Mendes - Cognitive assessment.

José Ibiapina Siqueira-Neto - Study design, manuscript writing and revision.

Valéria Sousa - Statistical analysis.

Anina Amaral - Statistical analysis.

Carolina Gomes Carrilho - Data revision, manuscript writing.

Jonatan Oliveira Espindola - Data discussion. Maria Eduarda Avancini Casali - Manuscript revision. André Barciela Veras - Study design, manuscript revision. Gilberto Sousa Alves - Study design, manuscript writing and final revision. 


\section{CONFLICT OF INTEREST STATEMENT}

The authors have no conflict of interest to declare.

\section{ACKNOWLEDGMENTS}

We thank all patients and family members who agreed to participate in this study.

\section{FUNDING STATEMENT}

The research project did not receive any funding.

\section{REFERENCES}

1. Herrera E, Caramelli P, Silveira ASB, Nitrini R. Epidemiologic survey of dementia in a community-dwelling Brazilian population. Alzheimer Dis Assoc Disord. 2002 Jun;16(2):103-8

2. Chaves MLF, Chaves MLF. Cognitive assessment in severe dementia and lower levels of education: reducing negligence. Arq Neuropsiquiatr. 2014;72(4):267-8.

3. Instituto Brasileiro de Geografia e Estatística - IBGE. Censo Demográfico do Município de Fortaleza [Internet]; 2010 [cited 2015 Jun 13]. Available from: http://www.cens02010. ibge.gov.br/sinopse/index. .php?uf $=23 \&$ dados $=1$

4. Instituto Brasileiro de Geografia e Estatística - IBGE. Censo Demográfico Brasileiro [Internet]; 2010 [cited 2015 Jun 13]. Available from: http://www.cens02010.ibge.gov.br/ apps/mapa/

5. Nelson PT, Head E, Schmitt FA, Davis PR, Neltner JH, Jicha GA, et al. Alzheimer's disease is not "brain aging": neuropathological, genetic, and epidemiological human studies. Acta Neuropathol. 2011;121(5):571-87.

6. Petersen RC. Mild cognitive impairment as a diagnostic entity. J Intern Med. 2004 Sep;256(3):183-94.

7. Petersen RC, Roberts RO, Knopman DS, Boeve BF, Geda YE, Ivnik RJ, et al. Mild cognitive impairment: ten years later. Arch Neurol. 2009 Dec;66(12):1447-55.

8. Albert MS, DeKosky ST, Dickson D, Dubois B, Feldman HH, Fox NC, et al. The diagnosis of mild cognitive impairment due to Alzheimer's disease: recommendations from the National Institute on Aging-Alzheimer's Association workgroups on diagnostic guidelines for Alzheimer's disease. Alzheimers Dement. 2011 May;7(3):270-9.

9. Scazufca M, Almeida OP, Vallada HP, Tasse WA, Menezes PR. Limitations of the Mini-Mental State Examination for screening dementia in a community with low socioeconomic status: results from the Sao Paulo Ageing \& Health Study. Eur Arch Psychiatry Clin Neurosci. 2009 Feb;259(1):8-15.

10. Unverzagt FW, Gao S, Baiyewu 0, Ogunniyi A0, Gureje 0, Perkins A, et al. Prevalence of cognitive impairment: data from the Indianapolis Study of Health and Aging. Neurology. 2001 Nov 13;57(9):1655-62.

11. Markesbery WR, Schmitt FA, Kryscio RJ, Davis DG, Smith CD, Wekstein DR. Neuropathologic substrate of mild cognitive impairment. Arch Neurol. 2006 Jan;63(1):38-46.

12. Chaves ML, Camozzato AL, Godinho C, Piazenski I, Kaye J. Incidence of mild cognitive impairment and Alzheimer disease in Southern Brazil. J Geriatr Psychiatry Neurol. 2009 Sep;22(3):181-7.

13. Robert P-H, Schuck S, Dubois B, Lépine J-P, Gallarda T, Olié J-P, et al. Validation of the Short Cognitive Battery (B2C). Value in screening for Alzheimer's disease and depressive disorders in psychiatric practice. L'Encéphale. 2003 Jun;29(3 Pt 1):266-72.

14. Brucki SMD, Nitrini R, Caramelli P, Bertolucci PHF, Okamoto IH. Suggestions for utilization of the mini-mental state examination in Brazil. Arq Neuropsiquiatr. 2003 Sep;61(3B):777-81.
15. Almeida OP. The Mini-Mental State Examination and the Diagnosis of Dementia in Brazil. Arq Neuropsiquiatr. 1998 Sep;56(3B):605-12.

16. Apolinario D, Mansur LL, Carthery-Goulart MT, Brucki SMD, Nitrini R. Detecting limited health literacy in Brazil: development of a multidimensional screening tool. Health Promot Int. 2014 Mar;29(1):5-14.

17. Brito-Marques PR de, Cabral-Filho JE. Influence of age and schooling on the performance in a modified Mini-Mental State Examination version: a study in Brazil northeast. Arq Neuropsiquiatr. 2005 Sep;63(3A):583-7.

18. Caldas VV de A, Zunzunegui MV, Freire A do NF, Guerra RO. Translation, cultural adaptation and psychometric evaluation of the Leganés cognitive test in a low educated elderly Brazilian population. Arq Neuropsiquiatr. 2012 Jan;70(1):22-7.

19. Sayegh P, Knight BG. Cross-cultural differences in dementia: the Sociocultural Health Belief Model. Int Psychogeriatr. 2013 Apr;25(4):517-30.

20. Carvalho VA, Mariano LI, Lima-Silva TB, Guimaraes HC, Cruz de Souza L, Barbosa MT, et al. The addenbrooke's cognitive examination-revised (ACE-R) in the diagnosis of mild cognitive impairment due to Alzheimer's disease: a preliminary analysis. Alzheimer's Dement [Internet]. 2017 Jul [cited 2018 Apr 8];13(7):P1138. Available from: http:// linkinghub.elsevier.com/retrieve/pii/S1552526017318940

21. Pfeffer Rl, Kurosaki TT, Harrah CH, Chance JM, Filos S. Measurement of Functional Activities in Older Adults in the Community 1. 1982;37(3):323-9.

22. American Psychiatric Association. Diagnostic and Statistical Manual of Mental Disorders. Fourth Edition: DSM-IV-TR ${ }^{\circledR}$. American Psychiatric Pub; 1994.996 p.

23. The ICD-10 Classification of Mental and Behavioural Disorders: Clinical Descriptions and Diagnostic Guidelines. World Health Organization; 1992. 380 p.

24. Instituto Brasileiro de Geografia e Estatística - IBGE. Síntese dos indicadores sociais: análise das condições de vida da população brasileira. Ministério do Planejamento, Desenvolvimento e Gestão; 2016.

25. Youden WJ. Index for rating diagnostic tests. Cancer. 1950 Jan;3(1):32-5.

26. Meyers LS, Gamst G, Guarino AJ. Data analysis using SAS Enterprise guide. Cambridge; New York: Cambridge University Press; 2009. 378 p.

27. Alexopoulos P, Ebert A, Richter-Schmidinger T, Schöll E, Natale B, Aguilar CA, et al. Validation of the German revised Addenbrooke's cognitive examination for detecting mild cognitive impairment, mild dementia in alzheimer's disease and frontotemporal lobar degeneration. Dement Geriatr Cogn Disord. 2010;29(5):448-56.

28. Amaral-Carvalho V, Caramelli P. Normative data for healthy middle-aged and elderly performance on the Addenbrooke Cognitive Examination-Revised. Cogn Behav Neurol Off J Soc Behav Cogn Neurol. 2012 Jun;25(2):72-6.

29. Carvalho VA, Caramelli P. Brazilian adaptation of the Addenbrooke's Cognitive ExaminationRevised (ACE-R). Dement Neuropsychol. 2007 Apr-Jun;1(2):212-6.

30. Carvalho VA. Addenbrooke's Cognitive Examination-Revised (ACE-R): adaptação transcultural, dados normativos de idosos cognitivamente saudáveis e de aplicabilidade como instrumento de avaliação cognitiva breve para pacientes com doença de Alzheimer provável leve [doctorate degree]. São Paulo: Universidade de São Paulo; 2009. Available from: http://www.teses.usp.br/teses/disponiveis/5/5138/tde-09122009-153803/pt-br.php

31. César KG, Yassuda MS, Porto FH, Brucki SM, Nitrini R. Addenbrooke's cognitive examinationrevised: normative and accuracy data for seniors with heterogeneous educational level in Brazil. International psychogeriatrics. 2017 May;29(8)1345-53.

32. Yu L, Wilson RS, Han SD, Leurgans S, Bennett DA, Boyle PA. Decline in Literacy and Incident AD Dementia Among Community-Dwelling Older Persons. J Aging Health. 2018;30(9):1389-405

33. Manly JJ, Touradji P, Tang M-X, Stern Y. Literacy and memory decline among ethnically diverse elders. J Clin Exp Neuropsychol. 2003 Aug;25(5):680-90.

34. Hall CB, Derby C, LeValley A, Katz MJ, Verghese J, Lipton RB. Education delays accelerated decline on a memory test in persons who develop dementia. Neurology. 2007 Oct 23;69(17):1657-64.

35. Tucker-Drob EM, Johnson KE, Jones RN. The cognitive reserve hypothesis: A longitudinal examination of age-associated declines in reasoning and processing speed. Dev Psychol. $2009 \mathrm{Mar} ; 45(2): 431-46$. 


\section{SUPPLEMENTARY MATERIAL}

Table 1. Accuracy, sensitivity, and specificity of ACE-R

\begin{tabular}{lcccccccc}
\hline Group Comparison & AUC & $\begin{array}{c}\text { Optimal } \\
\text { Cutoff }\end{array}$ & Sensitivity & Specificity & significance & IC & LR+ & LR- \\
\hline Controls versus MCl & 0.69 & $<57.5$ & 0.80 & 0.66 & $<0.001$ & $0.61-0.83$ & 2.35 & 0.30 \\
MCl versus Mild Dementia & 0.86 & $<49.5$ & 1.00 & 0.74 & $<0.001$ & $0.72-1.0$ & 3.85 & 0.00 \\
Control versus Mild Dementia & 0.98 & $\leq 50$ & 1.00 & 0.96 & $<0.001$ & $0.93-1.00$ & 25 & 0.00 \\
\hline
\end{tabular}

Table 2. Accuracy, sensitivity, and specificity of MMSE

\begin{tabular}{lcccccccc}
\hline Group Comparison & AUC & $\begin{array}{c}\text { Optimal } \\
\text { Cutoff }\end{array}$ & Sensitivity & Specificity & significance & IC & LR+ & LR- \\
\hline Controls versus MCl & 0.69 & $<26.5$ & 0.96 & 0.34 & $<0.001$ & $0.60-0.84$ & 1.45 & 0.12 \\
MCl versus Mild Dementia & 0.84 & $<19.5$ & 0.89 & 0.85 & $<0.001$ & $0.65-1.00$ & 5.93 & 0.13 \\
Controls versus Mild Dementia & 0.96 & $\leq 20$ & 0.89 & 1.00 & $<0.001$ & $0.88-1.00$ & 89 & 0.11 \\
\hline
\end{tabular}

Table 3. Accuracy, sensitivity, and specificity of the ACE-R in the Brazilian literature

\begin{tabular}{lccccccc}
\hline & Author & Group comparison & AUC & Sensitivity & Specificity & LR+ & LR- \\
\cline { 2 - 7 } Caramelli et al. 2017 & Controls versus MCl & 0.75 & 1.00 & 0.46 & 1.85 & 0.00 & 0.84 \\
& MCl versus AD & 0.74 & 0.60 & 0.84 & 3.80 \\
& & Controls versus AD & 0.86 & 0.78 & 0.79 & 3.81 & 0.28 \\
\hline
\end{tabular}

AD: Alzheimer's Dementia; MCl: Mild Cognitive Impairment. 